\title{
Analysis on Assimilation in and Countermeasure Research in Modern Design Education
}

\author{
Huazheng Liu
}

Communication and animation Institute, Qingdao University of Science and Technology, No.99, Songling Road, Laoshan District, Qingdao, Shandong Province , China

liuhuazheng1949@163.com

Keywords: Design education; Assimilation; Differences; Innovation

\begin{abstract}
The paper spreads the discussion about the theme of assimilation education in modern design education, summarizes several phenomena existing in assimilation education, expounds on lacking differentiated school-running thinking, simplified teaching contents and others reasons for the assimilation phenomena, based on it, points out that innovation is the fundamental measure of reforming assimilation education. The major of design has a greater demand for innovation ideas than other ones. The reforms of education thoughts and teaching methods can equip students with the innovation consciousness and ability and enhance China's design education level.
\end{abstract}

\section{Introduction}

With the advancement of the human society and rapid economic development, today's design education seems much more important than it did in any other pervious times, there are different education ideas for design education in different times. The development status in current China requires design education to focus on the cultivation of students' innovation ability. Innovation is the best approach of avoiding assimilation. To adapt to the diversified social demands, it is necessary to attach great importance to the innovative and differentiated teaching which can exert students' personalities and creativity in the current design education implementation, which is exactly the priority of China's modern design education.

\section{Assimilation Phenomena in Design Education}

The School-Running Patterns Are Assimilated, and the Teaching Standards Are Vague. The school-running patterns in the current domestic design major lack creativity and features and are simplified, they just inherit the traditional teaching patterns and lack advanced school-running concepts. What is most fundamental and important is it is necessary to suit China's national situation and run schools with our own features. The unfeatured education is assimilation education which has no vitality and lacks competitiveness, plagiarism or imitation is never the nature of design, so is education.

The Methods of Analyzing and Solving Problems Are Simplified. The specialty courses in university follow the rule: from simple design in the sophomore year to complicated design in the junior year and more in-depth design in the senior year. At the stage of preliminary design, students generally lack experience to judge the available solutions for problems, and think about them with the most common thinking set, rather than thinking about several solutions for one problem. This causes the phenomenon that student have the same ideas about one and the same topic. In the stage of in-depth design, they naturally accumulate some experience. but experience is always the bottleneck that restricts students' thinking breakthroughs and results in narrow design thoughts. The phenomenon of thinking assimilation appears in different stages. One of the important abilities for good designers is the broad thinking, namely, they don't stick to conventions, but try to think about and do what others don't. 


\section{Reasons for Assimilation Phenomena in Design Education}

Lack the Systematic Design Teaching. Systematic teaching means that different teaching levels have different levels of prescribed operable teaching design methods and techniques. At present, many domestic art colleges have no concrete operable teaching arrangement from the freshman year to the senior year, namely from basic teaching to specialty teaching, from classroom instruction to specialized practice, and from theories to specialty, they offer the mostly same courses, and divide majors too narrowly, not to mention systems and levels. Students know little about the other relevant majors, and their knowledge structure is too simplified, as a consequence, they cannot digest the major thoroughly which becomes the fetter of thinking innovation.

Lack the Differentiated School-Running Thinking, and the Regional Features Are Bright. Difference is the starting point of innovation, the basic point for realizing the self-brand and individualized design education, and the fundamental do solve assimilation education. To highlight the school-running features cannot be separated from the macro environment of economic development; it is necessary to combine the actual current situations and resources, absorb the world's advanced school-running ideas, recognize the self and effectively integrate with the local features to offer targeted majors. Only in this way, can positioning be more accurate.

The Students Have Weak Foundation. Design education should value the improvement of students' innovation ability, observation and analysis abilities and aesthetic taste, which are closely linked with actual learning. The basic education before students go to university doesn't well integrate science with cultural art vision, or combine the instruction of knowledge and skills with the cultivation of creativity. This causes the situation that many students don't have sufficient stamina in the specialty learning, excessively depend on computers and have weak operational ability.

\section{Implement the Concrete Measures in Teaching Reform}

Innovation is the fundamental measure of reforming assimilation education. The major of design has a greater demand for innovation ideas than other ones. Innovation is the nature of design, so is teaching.

Implement the Targeted Teaching, Setup Specialties be According to the Local Conditions, and Highlight the Features. Only when it keeps up with the pace of economic development, can design education step into the benign pathway and move forward steadily. Dr. David John, the President of the University of Luton, said: "the key to success for a university is that it can make its own school-running policy according to the actual demands of economic globalization." Using the western United States as the example, there are over 7000 companies, including Intel, Apple, etc., whose annual GDP is 480 billion dollars. Besides, the total output value of the entertainment industry in Los Angeles and other cities also reaches 100 billion dollars. The enormous market stimulates the demand for the design talents and also promotes the necessary reform of design education. Art Center College of Design (ACCD) located Los Angeles takes the lead, transfers its education priority to the multimedia design, sets the majors of multimedia, digital film trick, digital game design, etc. It is the quality reform of design education, as new majors are beneficial to both the society and promoting the development of design education.

Value Process over Result. The bold imagination and constant practices are always the prerequisite for great works. Teachers should not decide students' academic performance only by the final work effects. The Japanese Hiroshi Takahashi said: "The central strategy and advantage of the creative "practical" technology is the long-term preparation." The early design stage is the main process of preparation and creativity, there will be many shining points and good ideas through drawing a huge amount of drafts. The thinking process is the innovation process and also the process of difference emergence.

Correctly Treat Different Students, Implement the Individualized Teaching, and Have a Definite Teaching Target. Respect for students' personalities is the return of educational humaneness. The educational objects are real, thoughtful and affectionate people. Teachers should 
implement the individualized teaching according to different objects, adapt to students personalized demands, protect their personality development, and develop their potentials, make students' all good creation desires be respected, their creation activities supported, their creation talents exerted, and their creation achievements recognized. Art design is a discipline which emphasizes innovation and personality, which requires the educators to respect individuals and implement the differentiated teaching.

Establish the Diversified Curriculum Systems, Enrich the Teaching Contents, and Create the Brand Courses. Teachers should do their best to conduct teaching at high points of view, try the integration of the basic and specialty courses of different majors, and strengthen and deepen the basic theoretic teaching of humanistic ideas. Teachers should take both traditional culture and arts as the teaching contents, such as the beauty of artistic conception, beauty of language, beauty in form, etc., all of which can help the current students lay a solid creation foundation and bring useful enlightenment to them. Besides, it is necessary to separately set the contents of specialty courses according to different features of liberal arts and science, and implement the heuristic teaching which focuses on the exertion of students' personalities and creativity. In the practical teaching, teachers should study the basic design course with common features, strengthen the curriculum management and create the brand courses according to schools' features and students' demands, which create conditions for students' autonomic learning and personality development.

\section{Conclusions}

To sum up, the phenomenon of assimilation education in design education is an important issue in the current education field and arouses our rethinking about our current education systems, teaching patterns and teaching contents. Design is a comprehensive interdiscipline and doesn't have a standard system. Our modern design education should be set according to the national situation and times develop based on the market demand, and always in the state of pursuing new development. Therefore, continuous innovation is the core of design education; difference is the starting point of innovation, and also the fundamental measure to overcome the assimilation phenomenon in design education. Innovation cultivates students' ability of analyzing and solving problems; innovation allows design colleges to gradually have their own school-running features; and innovation makes our design education constantly develop and reach the world's advanced level.

\section{Acknowledgements}

Art key projects of Shandong Province, 2015. Item identification number: 1506256

\section{References}

[1] Jia Ronglin. Reexamination of Training Objectives of Art Design Education. Hubei Fine Arts Publishing House, 2005.11-7

[2] Wang Shouzhi. Current Design Education. China Youth Publishing House, 2002.9-2

[3] Xia Bing. Strengthen the Professional Orientation Education of the Major of Art Design in Independent Colleges. Hubei Fine Arts Publishing House, 2005.11-82

[4] Wang Xueqing. New Exploration of Basic Teaching for Design in China Academy of Art (CAA) - Sketch. China Academy of Art Press, 2007.3-1

[5] Luo Xianguo. Think about in A New System of Art Design Education, extracted from Program of Teaching System Reform of School of Art \& Design of Dalian Polytechnic University. China Textile Press, 2002.3

[6] Wang Wanxing, Kang Xiuji. Special Field Course Multi-Media Teaching System Exploitation and Application. Hubei Fine Arts Publishing House, 2005.11-113 
[7] TASCHEN Japanese Graphics Now!, 2007.2

[8] Takashi Murakami My Reality: Contemporary Art and the Culture of Japanese Animation

[9] Takashi Murakami Superflat (Japanese Edition)

[10] Susan Edelstein Kyozon: Mariko Mori, Takashi Murakami (Paperback) 